\title{
Investigation of Optimal Aspect Ratio and Optimal Number of Fins for Thermal Performance of Finned-Concentric-Tube Thermal Energy Storage ${ }^{\dagger}$
}

\author{
Jawad Rabbi *므, Muhammad Asif and Wajeeha Bibi
}

\author{
Faculty of Mechanical Engineering, GIK Institute of Engineering Sciences and Technology, Topi 23460, Pakistan; \\ masif@giki.edu.pk (M.A.); gme2124@giki.edu.pk (W.B.) \\ * Correspondence: jawad.rabbi26@gmail.com \\ † Presented at the 1st International Conference on Energy, Power and Environment, Gujrat, Pakistan, \\ 11-12 November 2021.
}

\begin{abstract}
This research focuses on the enhancement of the heat transfer in the concentric tube type of thermal energy storage (TES). The collective influence of the aspect ratio and number of fins is investigated. First, an optimal aspect ratio of the concentric tube TES is found. Additionally, then, the optimal number of fins is found. This combined optimal configuration of TES is then compared with concentric tube TES without. Liquid fraction of the combined optimal configuration was increased by $100 \%$ for case of charging as compared to TES without fins.
\end{abstract}

Keywords: thermal energy storage; PCM; aspect ratio; concentric tube; fins

check for updates

Citation: Rabbi, J.; Asif, M.; Bibi, W. Investigation of Optimal Aspect Ratio and Optimal Number of Fins for Thermal Performance of Finned-Concentric-Tube Thermal Energy Storage. Eng. Proc. 2021, 12, 4. https://doi.org/10.3390/ engproc2021012004

Academic Editor: Sajjad Miran

Published: 20 December 2021

Publisher's Note: MDPI stays neutral with regard to jurisdictional claims in published maps and institutional affiliations.

Copyright: (c) 2021 by the authors. Licensee MDPI, Basel, Switzerland. This article is an open access article distributed under the terms and conditions of the Creative Commons Attribution (CC BY) license (https:/ / creativecommons.org/licenses/by/ $4.0 /)$.

\section{Introduction}

Owing to the importance of thermal energy, engineers and scientists have worked tirelessly for centuries, trying to optimize the methods of producing thermal energy. However, the methods of producing thermal energy are not without drawbacks. In certain cases, external factors such as geography and climate also restrict the development of heating or thermal energy systems for use in practical situations, so novel methods need to be explored. One of the solutions to many challenges related to thermal energy and its management is TES. It is of two types-sensible heat storage (SHS) and latent heat thermal energy storage (LHTES) [1-3]. LHTES or phase-change materials (PCMs) can store more energy as compared to SHS. TES based on concentric tube is one of the most common TES configurations [4]. The most common problem of the LHTES is inefficient heat transfer between HTF and PCM. This poor heat transfer was showed by A. Trp (2005) [5], which in shell and tube type TES a big portion of the heat was carried with heat transfer fluid without transferring it to the phase change material. To overcome this challenge, various heat transfer methods have been proposed, and amongst them, the addition of fins is the most common method.

Rabbi and Asif [6] numerically investigated the influence of various heat transfer fluids and fins made up of copper mesh on the charging/discharging time. The results revealed that HTF with higher values of thermal diffusivity causes less charging and discharging time and that mesh type fins also decreased the charging time. Recently, Al-Mudhafar et al. [7] numerically investigated the effects of tee-shaped fins in shell and tube heat exchanger TES, various configurations were studied while total heat transfer area of fins was kept constant. Results indicated that tee-shaped fins reduced the charging time by $33 \%$ as compared to longitudinal fins. Similarly, Yang et al. [8] experimentally and numerically studied the thermal performance of concentric tube TES. Results showed that non-uniform arrangement of annular fins reduced inhomogeneity of melting process, and the charging time was decreased by $62.8 \%$ as compared to the TES with uniform fins. Eslamnezhad and Rahimi [9] numerically studied the effect of fins on heat transfer 
in triplex tube heat exchanger, they suggested the best type of arrangement to increase efficiency of heat exchanger and reduce the time of melting of the phase-change material in the form of different proposed models.

After the literature review, it is obvious that the collective impact of aspect ratio and optimal number of fins in concentric tube on the TES has not been investigated. Therefore, investigating the impact of aspect ratio and the addition of fins together is important. The main objective of this study is to analyze the influence of aspect ratio and fins in concentrictube-type TESs on the liquid fraction of PCM. A concentric tube TES with paraffin as a PCM was mathematically modeled. TES was charged and discharged with water as the HTF of constant temperature. First, the optimal aspect ratio is determined, and then optimal number of fins is found; next, this combined optimal TES configuration is compared with the TES without fins.

\section{Model Description}

The design consists of a simple concentric tube heat exchanger. The length of heat exchanger tube is $1 \mathrm{~m}$, and the inner mean diameter and outer mean diameter of tube is $0.06 \mathrm{~m}$ and $0.16 \mathrm{~m}$, respectively. Hot water flows inside the inner tube at $0.01 \mathrm{~m}^{3} / \mathrm{s}$, and PCM is kept between inner and outer tube. The heat transfer simulation is performed for both simple concentric tube heat exchanger and finned type heat exchanger using ANSYS Fluent 18.1, and the liquid fraction is noted down after the $120 \mathrm{~min}$.

\section{Results and Discussion}

\subsection{Effect of Aspect Ratio on TES Performance}

To improve the heat transfer, the aspect ratio of TES is studied. After performing the simulations for $120 \mathrm{~min}$, the resulting liquid fractions is noticed. Initially, the rate of increase of the liquid fraction is higher, but as the aspect ratio increases beyond 11, the rate of increase of the liquid fraction decreases. Therefore, optimal aspect ratio for TES is found to be 11. Results are shown in Figure 1.

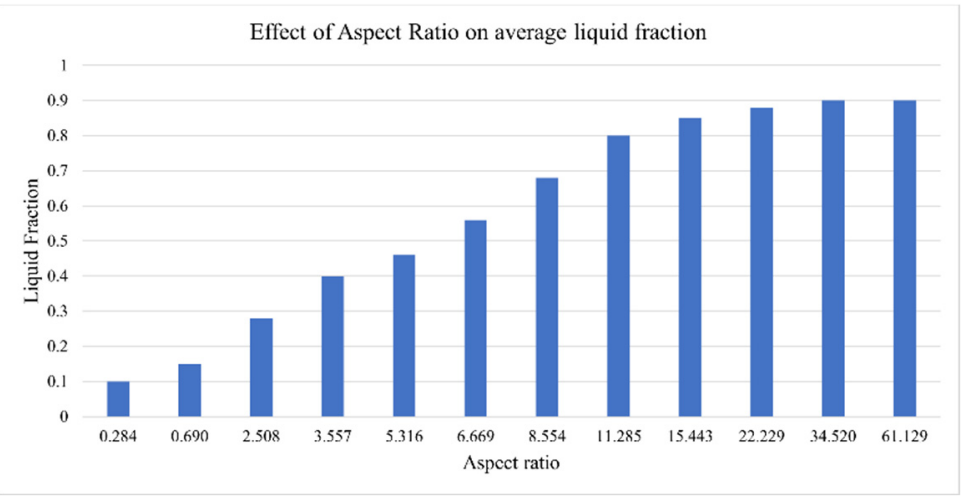

Figure 1. Effect of aspect ratio on liquid fraction for time $=120 \mathrm{~min}$.

\subsection{Influence of Number of Fins on TES Performance}

Fins are incorporated to enhance heat transfer by conduction. Optimized number of fins is found by performing simulations with varying number of fins. The resulting liquid fraction in $120 \mathrm{~min}$ is observed. Figure 2 indicates that as the number of fins is increased, the liquid fraction increase, which means that heat transfer increases. However, it is visible from the Figure 2 that as the number of fins is increased beyond eight, the increase of the liquid fraction is not significant. Therefore, eight fins are considered optimal for enhancing the heat transfer. 


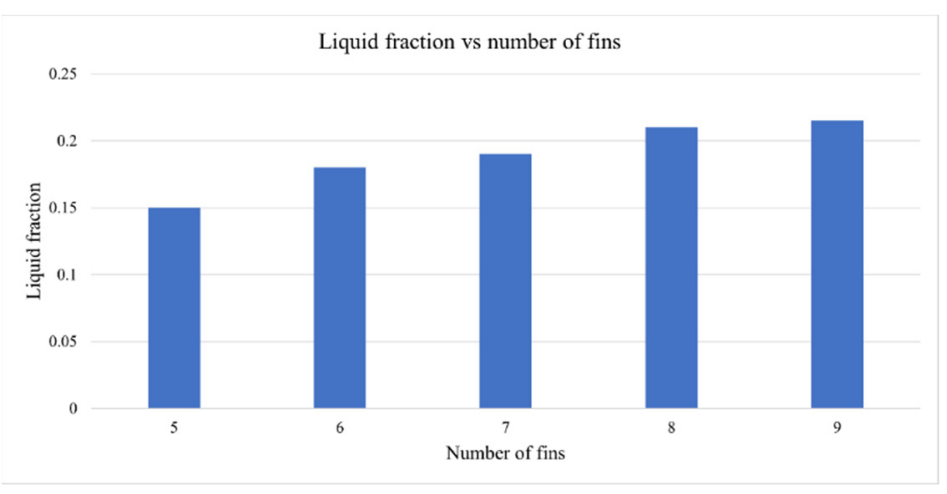

Figure 2. Effect of number of fins on liquid fraction at time $=120 \mathrm{~min}$.

\subsection{Comparison of Charging between Optimal Configuration and TES without Fins}

Inlet temperature of water is kept constant at $330 \mathrm{~K}$ to maximize the heat transfer. The mass flow rate of the water is kept at $0.01 \mathrm{~m} / \mathrm{s}$. The PCM temperature for concentric-tube TES without fins reached about $312.5 \mathrm{k}$ after $120 \mathrm{~min}$. Similarly, for an optimal configuration, the aspect ratio is 11 and the number of fins is eight: the PCM temperature reached about $315 \mathrm{~K}$ after $120 \mathrm{~min}$. This comparison at point (a) is shown in Figure 3. The average liquid fraction for concentric tube TES without fins reached about 0.4 , which indicates that 40 percent of the PCM melted after $120 \mathrm{~min}$. Similarly, for an optimal configuration, the aspect ratio is 11 and the number of fins is eight. The average liquid fraction reached about 0.8 , which indicates that $80 \%$ of the PCM melted after $120 \mathrm{~min}$. In $120 \mathrm{~min}, 100 \%$ more PCM was melted by using optimal TES configuration. Figure 4 shows phase of PCM in TES with and without fins at $120 \mathrm{~min}$, respectively.

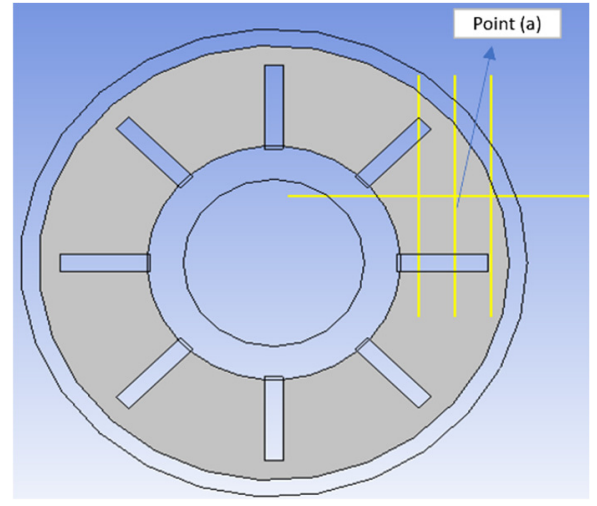

(A)

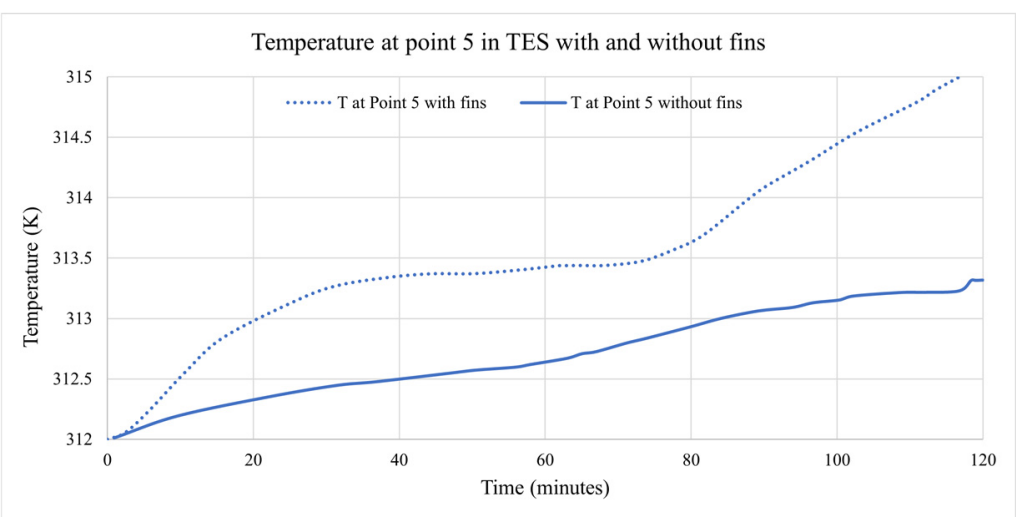

(B)

Figure 3. (A) Location of point (a) in thermal energy storage (TES). (B) Comparison between temperature of paraffin in TES with and without fins at point (a) for charging. 

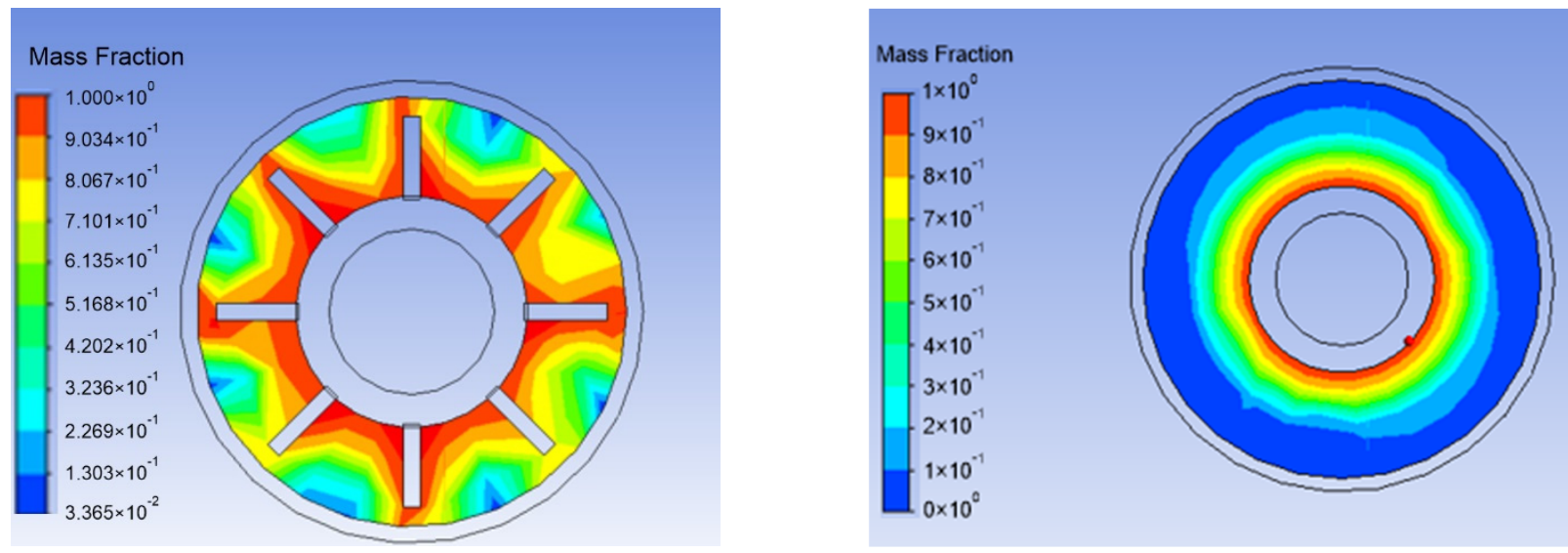

Figure 4. (a) Contour of liquid fraction of TES with fins. (b) Contour of liquid fraction of TES without fins.

\section{Conclusions}

In this research, the design of a concentric tube heat exchanger based on PCM was investigated numerically. Several configurations to improve heat transfer such as various aspect ratios and fins were investigated and compared. Simulation results prove that the application of finned heat exchanger was more effective in utilizing the latent heat energy. It was found that at eight fins and an aspect ratio of 11 , liquid fraction was at its maximum. Charging of this optimal configuration caused 100 percent more liquid fraction in 120.

Data Availability Statement: The data presented in this study are available on request from the corresponding author.

Conflicts of Interest: The authors declare no conflict of interest.

\section{References}

1. Pardo, P.; Deydier, A.; Anxionnaz-Minvielle, Z.; Rougé, S.; Cabassud, M.; Cognet, P. A review on high temperature thermochemical heat energy storage. Renew. Sustain. Energy Rev. 2014, 32, 591-610. [CrossRef]

2. Sarbu, I.; Sebarchievici, C. A Comprehensive Review of Thermal Energy Storage. Sustainability 2018, 10, 191. [CrossRef]

3. De Gracia, A.; Cabeza, L.F. Phase change materials and thermal energy storage for buildings. Energy Build. 2015, 103, 414-419. [CrossRef]

4. Mehling, H.; Cabeza, L.F. Heat and Cold Storage with PCM; Springer: Berlin/Heidelberg, Germany, 2008.

5. Trp, A. An experimental and numerical investigation of heat transfer during technical grade paraffin melting and solidification in a shell-and-tube latent thermal energy storage unit. Sol. Energy 2005, 79, 648-660. [CrossRef]

6. Rabbi, J.; Asif, M. A numerical study on effects of heat transfer fluids, copper mesh in packed bed and porosity, on charging time of paraffin based packed bed thermal energy storage. Energy Storage 2021, 3, e254. [CrossRef]

7. Al-Mudhafar, A.H.N.; Nowakowski, A.F.; Nicolleau, F.C.G.A. Enhancing the thermal performance of PCM in a shell and tube latent heat energy storage system by utilizing innovative fins. Energy Rep. 2021, 7, 120-126. [CrossRef]

8. Yang, X.; Guo, J.; Yang, B.; Cheng, H.; Wei, P.; He, Y.L. Design of non-uniformly distributed annular fins for a shell-and-tube thermal energy storage unit. Appl. Energy 2020, 279, 115772. [CrossRef]

9. Eslamnezhad, H.; Rahimi, A.B. Enhance heat transfer for phase-change materials in triplex tube heat exchanger with selected arrangements of fins. Appl. Therm. Eng. 2017, 113, 813-821. [CrossRef] 